point. From the comprehensive literature in this field and from my own work, I concluded that cutaneous herpes simplex recurring at the same site was most likely to be cured by topical idoxuridine. I know of no evidence that idoxuridine used on one site has any influence on the development of herpes simplex in other areas.

DMSO is bacteriostatic and consequently one rarely sees the classical "pustular phase" in herpes zoster treated with idoxuridine in DMSO. This fact is of considerable clinical importance since the rate of healing and the degree of post-zoster scarring are both directly related to the amount of secondary bacterial infection. I have recently completed a trial to assess the efficacy of various strengths of idoxuridine in $100 \%$ DMSO in herpes zoster. The results will shortly be published in full; however, of 78 patients treated, only six developed pustulation, these being the only patients to develop prominent post-zoster scarring.

Dr. Juel-Jensen stresses that prolonged use of idoxuridine in DMSO may lead to maceration of the treated skin. Before becoming aware of this fact I used $20 \%$ idoxuridine in $100 \%$ DMSO four-hourly for 8-10 days on 10 patients with zoster. All developed maceration in the treated area, three progressing to full-thickness skin loss, of whom two required skin grafting. It must therefore be stressed that under no circumstances should topical idoxuridine in DMSO be applied for more than 3-4 days.-I am, etc.,

North Stafordshire Hospital Centre,

Stoke-on-Trent 1 Dawber, R. P. R., British Medical fournal, 1972,
4, 300.

SIR,-As a geriatrician I have had a lot experience of the great disability and pain (even to the point of suicide) caused by herpes zoster. The treatment with idoxuridine suggested by Dr. B. E. Juel-Jensen (17 February, p. 406) sounds very effective, but I doubt whether it will be readily available to general practitioners and there is also the disadvantage of its high cost.

Herpes zoster requires to be treated immediately it is diagnosed, and despite what Dr. Juel-Jensen says about the inadvisability of treatment with prednisolone, I have always found this to be very effective given in doses of, say, $40 \mathrm{mg}$ a day for 10-14 days. I would suggest that this procedure be seriously considered in severe cases until idoxuridine treatment becomes more readily available.-I am, etc.,

Bury General Hospital,

F. R. Glover

Bury, Lancs

\section{Infantile Overnutrition}

SIR,-Dr. Amnapurna Shukla and others (2 December, p. 507), reporting on 24-hour dietary recall and anthropometric measuremen's of 300 infants, concluded that overweight and obesity noted in $44.4 \%$ of their group might have been prevented had the babies not been overfed. Seeking to substantiate this conclusion we have examined fourday dietary histories and weight data from a survey of 374 infants under one year of age. This group was demographically balanced for age, socioeconomic status, and geographical distribution in the United States. The average caloric intake was $101 \pm 23 \mathrm{kcal} / \mathrm{kg}$ body weight with a wide range $(34-205 \mathrm{kcal} / \mathrm{kg})$.

To test the speculation that the heavier eaters were the heavier babies the body weights of the babies consuming $140 \mathrm{kcal} / \mathrm{kg}$ or more were compared with the body weigh:s of the babies consuming $70 \mathrm{kcal} / \mathrm{kg}$ or less. The heavier eaters, 20 in all, average age $7 \pm 4.3$ (S.D.) months, consumed an average of $1,097 \pm 416 \mathrm{kcal} /$ day and weighed $7.0 \pm 2.6 \mathrm{~kg}$. The lighter eaters, 16 in number, average age $6.6 \pm 3.1$ months, consumed an average of $575 \pm 135 \mathrm{kcal} /$ day but unexpectedly weighed $9.0 \pm 1.6 \mathrm{~kg}$.

Using the computer to prepare scatter plots showing the weight and age of these infants, the two groups were comcared. The computer-calculated regression lines very clearly show that heavier eaters were lighter in weight than the average for the entire group while the lighter eaters were heavier than the average (see fig.).

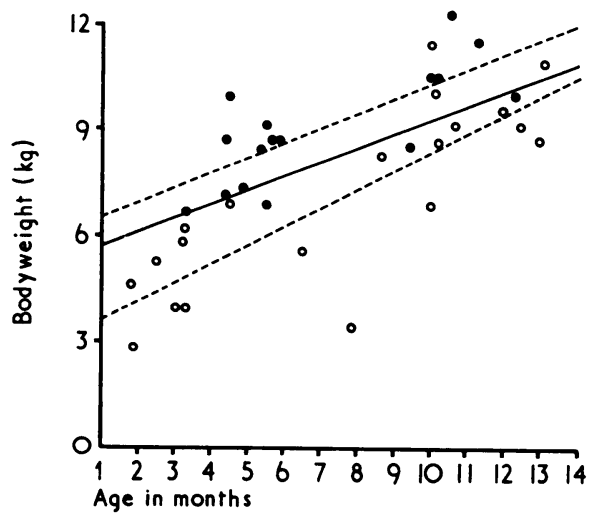

Computerplot showing weight and age of 16 infants receiving less than $70 \mathrm{kcal} / \mathrm{kg}$ body weight ( $\bullet$; upper line) and of 20 infants receiving more than $140 \mathrm{kcal} / \mathrm{kg}$ ( 0 ; upper line). The middle line represents the average weight of the entire group of 374 infants.

Accepting these observations at face value one is tempted to conclude that constitutional differences are more influential in determining body weight than caloric intake. Differences in activity, food absorption capacity, and metabolism undoubiedly account for some variability in body composition. On the other hand, in a truly definitive study not only the quantity but also the quality of nutrient intake over an extended period of time should be taken into account.

Recommended dietary allowances have been established as guidelines for population groups and may not be applicable for defining optimal nutrient intake of individuals. It would be interesting to compare the weights of the heavier versus the lighter feeders in Dr. Shukla's survey to either confirm or deny our anomalous observation. -We are, etc.,

Robert A. Stewart

Gerber Products Co.

GEORge A. PURvis

Fremont, Michigan

\section{Malignant Hyperpyrexia}

We were also interested in Dr. W. G.

SIR,-With great respect to Dr. W. G. Bradley's suggestion (24 February, p. 486)
Bradley 24 February, p. 486), I think he is that malignant hyperpyrexia was first confusing two entirely different, I think he is
"Late ether convulsions," so called to distinguush them from the innocuous "ether tremor" of light anaesthesia, was well recognized in the $19 \angle 0 \mathrm{~s}$ and was fully discussed at the Royal Society of Medicine in 1928 following a paper by the late Dr. Charles Hadfield. ${ }^{1}$ Although its exact pathology was not established, it was regarded as a type of heat stroke and was commonest in ohildren (e.g., those suffering from acute appendicitis) being operated upon in hot and stuffy theatres. Most of these patients had a high temperature before the induction of anaesthesia. During the second world war I worked one day a week at a provincial hospital in which the twin theatres on the top floor were lit by large skylights. During the blackout, ventilation was negligible and "ether convulsions" after dark became fairly frequent, usually three of four cases per week. The anaesihetists became alert to observe the first indications of facial twitching and started immediate treatment with a steep head-up position and cooling with ice-water and fan. Response was rapid and I do not think that any fa-alities occurred. The bla-k-out was removed on V.E. Day and during the following year not a single case of convulsions was observed.

"Malignant hyperpyrexia" on the other hand is another and much more sinister condition. Its appearance coincided with the introduction of halothane and suxamethonium, to which must now be added methoxyflurane. The mortality is extremely high, a recent analysis of over 300 cases yielding the alarming figure of over $60 \% .^{2}$

While convulsions have been reported after the use (or misuse) of practically every form of anaesthesia and analgesia, I do think that the two types mentioned should be distinguished.-I am, etc.,

\section{LANGton Hewer}

London N.6

1 Hadfield, C. F., Proceedings of the Royal Society
of Meticine, 1927/1928, 21. 1699.
2 Re!ton, J. E. S., Steward, D. J. Creighton, R.
E., and Britt, B. A., Canadian Anaesthetists
Society fournal, 1972, 19, 200.

SIR,-We would like to thank Drs. D. G. F. Harriman and F. R. Ellis ( 3 March, p. 545) for their comments on our paper on the pathology of malignant hyperpyrexia. We are interested to learn that they consider that the "moth-eaten fibres" which they have observed in a myopathy associated with malignant hyperpyrexia may be identical with the core lesions which we have described. If indeed their findings are the same as ours, we prefer to refer to these abnormal areas as cores, for the lesions that we have noticed have all the characteristic features of cores which have been described in the literature not only since 1970 , as Drs. Harriman and Ellis suggest, but as far back as 1956. We have not suggested that the presence of these cores is specific for the myopathy or myopathies associated with malignant hyperpyrexia, but we have found identical cores in two other patients who were also affected by a myopathy predisposing to malignant hyperpyrexia. that malignant hyperpyrexia was first described by Guedel in $1937,{ }^{1}$ but in fact there 